\title{
Optimal Crop Insurance Under Climate Variability: CONTRASTING INSURER AND FARMER INTERESTS
}

\author{
V. E. Cabrera, D. Solís，D. Letson
}

\begin{abstract}
This study illustrates the potential synergies and conflicts of interest between farmers and insurers in the selection of an optimal crop insurance contract. Special attention is given to how climate information influences this decision-making process. To do so, we consider a representative 40 ha, rainfed, cotton-peanut farm located in Jackson County, Florida. Our results show that year-to-year El Niño Southern Oscillation (ENSO) based climate variability affects farmers' and insurers' net returns according to crop insurance contracts. Introduction of ENSO-based climate forecasts presents a significant impact on the selection of a particular contract to both the farmer and the insurer. We conclude that insurers and farmers can bridge their divergent interests by improving their understanding of the effect of climate conditions on the development of sustainable business plans.
\end{abstract}

Keywords. Crop insurance, ENSO, Optimization analysis, Risk management.

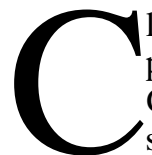

limatic variability significantly affects agricultural production, profitability, and risk (Hansen, 2002; Chen and Chang, 2005). Several studies have shown that agricultural management has been improved during the last years based on the prediction of seasonal climate (Baigorria et al., 2008; Podestá et al., 2002; Nnaji, 2001). Predictability of seasonal climate variations can help in reducing farm risk by tailoring agricultural management strategies to mitigate the impacts of adverse conditions or to take advantage of favorable conditions (Letson et al., 2005; Hill and Mjelde, 2002). In this respect, crop insurance offers farmers economic stability under the uncertainty of future random events, including climate (Mahul, 2001). However, optimal crop insurance choices for farmers differ from those of insurers. In addition, once farmers buy crop insurance, they have a greater incentive to engage in risky behavior; clearly moral hazard can cause farmers' and insurers' interests to diverge. Predictable climate variations may offer an opportunity to close this gap by improving some monitoring features of the crop insurance market (Fraser, 2004).

Previous research on the value of climate forecasts on the crop insurance market has been performed from either the farmer's or the insurer's viewpoints, but none have investigated the potential interactions between them. Thus, this article adds to the literature by evaluating optimal crop

Submitted for review in August 2007 as manuscript number IET 7171; approved for publication by the Information \& Electrical Technologies Division of ASABE in March 2009.

The authors are Víctor E. Cabrera, ASABE Member, Assistant Professor, Department of Dairy Science, University of WisconsinMadison, Madison, Wisconsin; Daniel Solís, Assistant Scientist, Division of Marine Affairs and Policy, Rosenstiel School of Marine and Atmospheric Science (RSMAS), University of Miami, Miami, Florida; and David Letson, Professor, Division of Marine Affairs and Policy, Rosenstiel School of Marine and Atmospheric Science (RSMAS), University of Miami, Miami, Florida. Corresponding author: Víctor E. Cabrera, Department of Dairy Science, University of Wisconsin-Madison, 1675 Observatory Drive Room 279, Madison, WI 53706; phone/fax: 608-265-8506; e-mail: vcabrera@wisc.edu. insurance strategies for farmers and insurers based on different climatic scenarios and levels of risk aversion. The goal of this study is to offer a thorough picture of the value of climate forecasts for the whole crop insurance market. Our hypothesis is that both conflicts and synergies exist between farmers and insurers regarding crop insurance selection and that they are influenced by climate variability.

To reach our goal, we analyze the case of a representative 40 ha, rainfed, cotton-peanut farm located in Jackson County, Florida. The southeastern U.S. offers an illustrative setting for studying the interaction of climate variability and crop insurance strategies. Several studies have shown that the El Niño Southern Oscillation (ENSO) is a strong driver of seasonal climate variability that impacts cotton and peanut crop yields in this geographical area (e.g., Hansen, 2002; Jones et al., 2000). In this study, we integrate biophysical simulation models and stochastic non-linear whole-farm optimization models to identify an optimum crop insurance product for farmers and insurers based on different scenarios for ENSO and levels for risk aversion. The riskiness of the decision strategies is evaluated using a constant relative risk aversion utility function for farmers (Letson et al., 2005) and a conditional value-at-risk model (CVaR) for insurers (Liu et al., 2008). These results are then contrasted to evaluate the synergies and conflicts between the two groups under study.

\section{LITERATURE REVIEW}

Most empirical studies on climate and crop insurance have focused on evaluating ways to reduce the farm risk associated with climate variability by selecting the most adequate crop insurance products. Among these studies, Mjelde et al. (1996) implemented a decision-making framework to introduce crop insurance programs along with climate forecast information. Mjelde and Hill (1999) then developed a catastrophic insurance study for corn and sorghum using utility functions under uncertain weather forecasts. Cabrera et al. (2007) evaluated the most common insurance products for maize, cotton, and peanuts in Florida under the uncertainty of future climate conditions. In addition, Cabrera et al. (2006) 
developed a model to select the best crop insurance products within a whole-farm portfolio framework. In general, these studies concluded that farmers could benefit significantly from using seasonal climate forecast information. Schneider and Garbrecht (2003) and Dalton et al. (2004) add that the federal crop insurance programs in the U.S. also need to incorporate this kind of information in order to deliver a more efficient assistance to farmers.

From the insurer's point of view, Ker and McGowan (2000) presented a model that dealt with adverse selection of crop insurances according to ENSO phases. Their results showed that economically and statistically significant excess rents may be garnered by insurance companies through weather-based adverse selection. In addition, Turvey et al. (1999) portrayed a model that evaluated insurer's risk and developed an approach to computing actuarial reinsurance premiums, and Abbaspour (1994) implemented a Bayesian risk methodology to help crop insurers cope with uncertainty and risk.

For the case of farmer/insurer interactions, only a limited number of studies exist, and none of them have formally included climate information in their analysis. Among these studies, Wang and Zhang (2003) contrasted farmer and insurer perspectives to evaluate the feasibility of non-subsidized, private crop insurance, and Menrad and Hirzinger (2005) compared the impacts of crop insurance for insurers and farmers under the scheme of genetically modified plants.

In sum, most empirical studies dealing with climate variation and crop insurance have analyzed this issue either from the farmer's or the insurer's perspective, and when interaction has been evaluated, climate has not been included into the analysis. In this article, we propose a more comprehensive analysis by contrasting both viewpoints in the selection of an optimal crop insurance product under the influence of climate variability.

\section{Materials ANd Methods}

\section{CASE STUdY AND DATA}

Two of the most cultivated crops in the southeastern U.S. are peanuts and cotton. These crops are traditional grown in this region under rainfed technology, making them extremely sensitive to climate variation and ideal for our study. Thus, to analyze the optimal selection of crop insurance under climatic uncertainty, we used a representative farm of 40 ha, rainfed, located in Jackson County, Florida. This farm grows $50 \%$ peanut (Arachis hypogaea L.) and 50\% cotton (Gossypium hirsutum L.) in Dothan loamy sand. This representative farm was designed taking into account similarities in environment, resources, and technology to other major agricultural production areas in the southeastern U.S., so our findings can be used as reliable proxies for a broader agricultural region.

Several authors, including Baigorria et al. (2008), Hansen (2002), Mavromatis et al. (2002), and Jones et al. (2000), have reported the effect of climate variability due to ENSO on crop yields in Florida. The ENSO is a climatic phenomenon characterized by changes in the sea surface temperature of the equatorial Pacific Ocean that influences the regional climate. Rainfall is especially sensitive to ENSO phases (i.e., El Niño, La Niña, and neutral) in Florida, with an above-average rainfall near $40 \%$ during an El Niño year, and with a below-average rainfall close to $30 \%$ during a La Niña year. Temperature is also affected by ENSO. Lower (higher) temperatures are observed during El Niño (La Niña) (Jagtap et al., 2002). These climatic changes are accentuated during the winter season (December-March) and consequently have a major affection to crops during planting and early growing season.

Crop yields depend on several factors, including technology, resources, planting dates, and weather conditions during the growing period. Therefore, predictability of seasonal climate variability gives the opportunity to forecast crop yields for different planting scenarios. In this study, crop yields for peanuts and cotton were simulated using a suite of biophysical simulation models (DSSAT v4.0; Jones et al., 2003) and daily weather records, which were classified by ENSO phase. Inputs for the simulation model followed the current management practices of variety, fertilization, and planting dates in the region, following Boote et al. (1998) for peanuts and Messina et al. (2003) for cotton.

The Japanese Meteorological Agency index (JMA, 1991) definition of ENSO events was used to sort the climate data. The JMA index defines El Niño events based on sea surface temperature (SST) anomalies in the region $4^{\circ} \mathrm{N}$ to $4^{\circ} \mathrm{S}$ and $150^{\circ} \mathrm{W}$ to $90^{\circ} \mathrm{W}$. An El Niño (La Niña) is identified when the five-month running average of SST anomalies is greater (lower) than $0.5^{\circ} \mathrm{C}$ for at least six consecutive months. The event must begin before September and include October, November, and December.

The climate data, which included 65 years (1939-2003) of daily rainfall, maximum and minimum temperatures, and solar radiation, were obtained from the weather station at Chipley, Florida. The limited duration of daily weather records provided only a few realizations of ENSO impacts on crop yields (i.e., 14 for El Niño, 16 for La Niña, and 35 for neutral years). In consequence, to obtain more robust results, we expanded the simulated data using a stochastic yield generator, as in Cabrera et al. (2006, 2007). Our stochastic yield generator employed re-sampling in three steps. First, crop yields simulated by crop models were sorted for an ENSO phase and a planting date. Second, a function (logarithmic, exponential, quadratic, or linear; whichever had a higher $\mathrm{R}^{2}$ ) was fit to the data. We used a mathematical function in order to avoid underestimating potential extreme values in the distribution. Third, 990 stochastic yields were generated by re-sampling a function. We repeated the procedure for each planting date, of each crop, in each ENSO phase.

The final crop yield records encompassed 990 cases for each ENSO phase, and consequently there were 2,970 records for "all years." Note that the synthetic series cannot include more information than the historical records they draw from. For example, the synthetic series would not offer advantage in the study of inter-decadal ENSO event frequency or strength. However, the synthetic series do confer advantage in our study because: (1) crop yields (and thus forecast value) are highly responsive to the arrangement of daily weather sequences, and (2) historical weather records offer only one of many possible realizations of the weather processes.

Table 1 presents a summary of the synthetically generated crops yields by ENSO phases and planting dates contrasted 
Table 1. Peanut and cotton synthetically generated and historical yields according to ENSO phases.

\begin{tabular}{|c|c|c|c|c|c|c|c|c|c|c|c|c|c|}
\hline \multirow{3}{*}{$\begin{array}{c}\text { Crop } \\
\text { (Variety) }\end{array}$} & & \multicolumn{12}{|c|}{ Yields $\left(\mathrm{kg} \mathrm{ha}^{-1}\right)$} \\
\hline & & \multicolumn{3}{|c|}{ All Years } & \multicolumn{3}{|c|}{ El Niño } & \multicolumn{3}{|c|}{ Neutral } & \multicolumn{3}{|c|}{ La Niña } \\
\hline & & Mean & SD & $n$ & Mean & SD & $n$ & Mean & SD & $n$ & Mean & SD & $n$ \\
\hline Peanut & Synthetic ${ }^{[a]}$ & 3241 & 1294 & 2970 & 3222 & 1283 & 990 & 3247 & 1356 & 990 & 3253 & 1216 & 990 \\
\hline (Georgia Green) & Historical $[\mathrm{b}]$ & 3155 & 1311 & 65 & 3103 & 1302 & 14 & 3161 & 1361 & 35 & 3170 & 1262 & 16 \\
\hline Cotton & Synthetic & 716.5 & 79.8 & 2970 & 705.5 & 76.5 & 990 & 731.3 & 76.5 & 990 & 713.3 & 82.0 & 990 \\
\hline (DP 555) & Historical & 703.2 & 83.4 & 65 & 692.6 & 79.1 & 14 & 743.5 & 79.6 & 35 & 701.1 & 85.3 & 16 \\
\hline
\end{tabular}

[a] Nine planting dates for peanuts and four for cotton were included in the simulation in addition to current management practices in the region for varieties and fertilization. More detailed information about the synthetic generated yields can be found in Cabrera et al. (2006).

[b] Historical crop production records are from NASS (2007).

with their historical records. It is important to indicate that the simulated yields are consistent with previous research in Florida (e.g., Cabrera et al., 2007; Mavromatis et al., 2002; Hansen et al., 1998) and with historical data (NASS, 2007). In both datasets, synthetic and historical, it is possible to observe differences in sample means for the alternative ENSO phases.

To simulate the necessary farm income series, synthetic prices series were generated according to Letson et al. (2005). In doing so, several steps were performed. First, monthly average prices received by Florida farmers for peanut and cotton were obtained from the USDA National Agricultural Statistics Service. Prices of cotton were increased by $18.66 \%$ to account for the seed value not included in the USDA statistics. The price series, which included data from January 1996 to January 2005, were deflated to January 2005 dollars using the U.S. Consumer Price Index. In addition, these data were de-trended for seasonal differences by estimating monthly residuals with respect to their means. Principal component analysis was used to decompose the matrix of price residuals and ENSO phases into three uncorrelated time series of amplitudes that were separately sampled. The sampled values were combined and back-transformed to reconstruct crop price residuals. The Kolgomorov-Smirnov tests confirmed that the correlation structure of the synthetic price residuals was similar to that of the historical data and that the historical price distributions were well reproduced according to quantile-quantile plots. Finally, seasonal price averages for the harvesting dates of the two crops were reintroduced: 2 September to 6 November for peanut, and 22 September to 28 December for cotton. The price distributions obtained with this method do not represent historical values, but rather distributions consistent with historical variability.

Contemporary local (variable and fixed) costs of production and labor requirements were deterministically incorporated in the model. The data for the two crops were provided by the North Florida Research and Education Center in Quincy, Florida. The annual variable costs for peanut and cotton are, respectively, $\$ 1,088 / \mathrm{ha}$ and $\$ 1,122 / \mathrm{ha}$. The fixed costs are $\$ 344 /$ ha for peanut and $\$ 177 /$ ha for cotton.

Lastly, to provide more realistic farm scenarios and to reduce the number of decisions in our model, the most common insurance products used by farmers in Jackson County were used in the analysis. Specifically, the studied crop insurance products for peanut and cotton were: CAT (catastrophic coverage) and $65 \%, 70 \%$, and $75 \%$ APH (actual production history, also known as MPCI, or multi-peril crop insurance). Additionally, 65\%, 70\%, 75\%, 80\%, and 85\% CRC (crop revenue coverage) was included for cotton. The farmer's choice of no insurance selection was also included in the model. In this study, we diverge from Cabrera et al. (2006) in which the premiums received by the insurer included both the government subsidies as well as the farmer's payment. Premiums were computed using the Premium Calculator at the USDA Risk Management Agency website (www3.rma.usda.gov/ apps/premcalc/).

\section{Methodology}

Two stochastic non-linear whole-farm models (farmer and insurer) were implemented to select optimal crop insurance combinations according to ENSO phases and risk aversion levels. The farmer and insurer models differed in the fact that each one accounted for their specific business goals. The farmer's case was evaluated by maximizing a constant relative risk aversion utility function (Cabrera et al., 2006), whereas the insurer's optimal choices were computed using a minimization of losses framework constrained by a CVaR model (Liu et al., 2008). These techniques are discussed in the following sections.

\section{Optimal Farm Decisions for the Farmer}

To evaluate the impact of climate information on the farm decision-making process and to estimate the value of crop insurance choices on farm net returns, we implemented a stochastic non-linear whole-farm model. This mathematical programming model was systematically solved to identify optimal planting dates and to simulate annual net returns based on the chance of forecasting a given phase for ENSO, available crop insurance products, and different levels of risk aversion. We assume that climate conditions and crop prices are unknown at the decision time but that their historical distributions are known. The model maximized the expected utility $(U)$ at the end of one-year planning horizon using the following objective function:

$$
\max E\left[U\left(W_{f}\right)\right]=\sum_{n=1}^{N} U \frac{W_{0}+\Pi_{i, n}}{N}
$$

$$
\text { for } n=1 \text { to } N ; i=1,2,3,4
$$

where

$$
\begin{gathered}
U\left(W_{f}\right)=\frac{W_{f}^{1-R_{r}}}{1-R_{r}} \\
\text { for } R_{r}=0,1,2,3,4 \\
\Pi_{i, n}=\sum_{j=1}^{2}\left(Y_{j} P_{j}+I Y_{j} P B_{j}-C_{j}-P r_{j}\right)\left(X_{j}\right)
\end{gathered}
$$


subject to

$$
\begin{aligned}
& \sum_{m=1}^{9} X_{m, j}=0.5, \sum_{m=10}^{13} X_{m, j}=0.5, X_{m} \geq 0 \\
& \text { for } j=1 \text {; for } j=2
\end{aligned}
$$

where

$$
\begin{aligned}
i= & \text { ENSO phase }(1=\text { El Niño, } 2=\text { neutral, } 3=\text { La Niña }, \\
& 4=\text { all years }) \\
j= & \text { crop }(1=\text { peanut, } 2=\text { cotton }) \\
m= & \text { planting date }(1 \text { to } 9 \text { for peanut: } 16,23 \text { April; } 1,8,15,
\end{aligned}
$$
22, 29 May; 5, 12 June) (10 to 13 for cotton: 16, 23 April; 1, 8 May)

$n$ = years for each optimization

$N=990$ for El Niño, neutral, and La Niña, and 2970 for all years

$R_{r}=$ constant risk aversion coefficient

$\Pi=$ net returns

$W_{0}=$ initial wealth

$W_{f}=$ final wealth

$Y=$ crop yield

$I Y=$ indemnity yield for insurance purposes (i.e., the compensation a farmer receives to cover losses be low insured yield levels)

$P=$ crop price

$P B=$ price base for insurance purposes

$C=$ production cost

$\mathrm{Pr}=$ insurance premium

$X=$ percentage of land allocation for every crop planting date.

We assessed the riskiness of the decision strategies by allowing the utility to be a power function of wealth, based on a constant relative risk aversion coefficient (eq. 2). Based on Hardaker et al. (2004), we considered five possible risk aversion levels: $R_{r}=0$ or risk neutrality, $R_{r}=1$ or normal aversion, $R_{r}=2$ or rather averse, $R_{r}=3$ or very averse, and $R_{r}=4$ or almost paranoid. Different risk levels are included in this analysis to assess the behavior of the farmer under climate uncertainty.

\section{Optimal Farm Decisions for the Insurer}

The insurer's case was also analyzed using a stochastic non-linear whole-farm model. In this case, the model was systematically solved to identify optimal planting dates to yield annual insurer-expected minimum losses for all combinations of ENSO phases and available crop insurance products. The model assumed that the farmer requires selecting at least some type of insurance contract for each cultivated crop. This procedure was repeated for each combination of peanut and cotton crop insurance product. The model minimized losses $(L)$ for one-year planning horizon, using the following function:

$$
\min _{x} E[L]=\sum_{n=1}^{N} \sum_{j=1}^{2} X_{m, i, j} I Y_{i, j} P B_{i, j}-X_{m, i, j} \frac{P r_{i, j}}{N}
$$

for $n=1$ to $N ; i=1$ to $4 ; m=1$ to 13

subject to

$$
\begin{aligned}
& \sum_{m=1}^{9} X_{m, j}=0.5, \sum_{m=10}^{13} X_{m, j}=0.5, X_{m} \geq 0 \\
& \text { for } j=1 ; \text { for } j=2
\end{aligned}
$$

$$
\operatorname{CVaR}_{\alpha}[L(\vec{x}, \vec{\xi})] \leq v
$$

where

$\vec{x}=\left\{X_{m}, \lambda_{j}\right\}$ is the decision vector

$\vec{\xi}=\left\{Y_{j}, P_{j}\right\}$ is the random vector

$\lambda_{j}=$ selection of insurance policy for crop $j$

$m$ = planting date (1 to 9 for peanut: 16, 23 April; 1, 8, 15, 22, 29 May; 5, 12 June) (10 to 13 for cotton: 16, 23 April; 1, 8 May)

$n$ = years for each optimization

$N=990$ for El Niño, neutral, and La Niña, and 2970 for all years.

To manage the insurer's risk levels within this framework, we implemented a CVaR model (Rockafellar and Uryasev, 2002). CVaR is a financial adaptation of the chanceconstrained programming for stochastic optimization models (Prekopa, 1995; Charnes and Cooper, 1959) developed to hedge a portfolio of financial instruments (crop insurances in our case) to reduce risk. The objective to minimize expected losses $(L)$ is constrained under a CVaR (eq. 7), so the insurer can control the risk $(\alpha)$ associated to a combination of insurance contracts to ensure that losses are no greater than a defined threshold $(v)$. In essence, CVaR is defined using the $\alpha$ percentile of a random variable. For a continuous random variable $\vec{\xi}$, its $\alpha$ percentile is the value $\zeta$ such that $P(\vec{\xi} \leq \varsigma)=\alpha$, where $P$ is the probability function. For instance, for a standard normal random variable $\vec{\xi}$, its 0.5 percentile is $\zeta=0$ and its 0.975 percentile is $\zeta=1.96$. The $\alpha$ percentile is called value-at-risk (VaR) in finance applications. However, for continuous distributions, conditional value-atrisk $(\mathrm{CVaR})$ is the average value of the random variable exceeding its $\alpha$ percentile. For instance, the $97.5 \% \mathrm{CVaR}$ of a standard normal random variable $\vec{\xi}$ is the expectation of $\vec{\xi}$ exceeding 1.96, or $E(\vec{\xi} \mid \vec{\xi}>1.96)$, where $E$ stands for the expectation (Liu et al., 2008). A more detailed mathematical derivation of the CVaR model in agriculture can be found in Rockafellar and Uryasev (2002).

Both optimization models (i.e., farmer's and insurer's) were solved using the MINOS5 algorithm in GAMS (Gill et al., 2000) along with a randomized procedure to alter starting values and ensure global maxima solutions. We ensured global maxima solutions through simulations performed with optimal coefficients. Every solution needed about 18,000 iterations. The optimum values (maximum expected utility for farmer and minimum expected losses for insurer) were binned by ENSO phase and risk aversion level and then ranked to select the best performing crop insurance combination.

\section{InSURANCE LOSS RATIO}

In this study, we also use the insurance loss ratio (LR) index to further analyze the potential synergies and conflicts between farmers and insurers. The LR is the proportion of received premiums that the insurer spends to pay indemnities. The LR is a fair measure of the value of an insurance product from a consumer perspective (Rupp, 1991). This index can be used to evaluate conflicts and synergies between farmer and insurer by depicting how much of the premium received by 
the insurer is collected as indemnity by the farmer. The LR can be calculated by dividing the indemnity by the premium:

$$
\mathrm{LR}_{i, n}=\sum_{j=1}^{2}\left(I Y_{j} P B_{j} X_{j}\right) /\left(P r_{j} X_{j}\right)
$$

The Federal Crop Insurance Corporation (FCIC) in 2005 targeted an overall acceptable LR of 1.075 , or $107.5 \%$. That is, crop insurance companies should be willing to pay $7.5 \%$ above the premium received, in the long run.

\section{Results AND Discussion}

\section{Farmer's Best Performing Crop Insurance Combinations}

Table 2 presents the farmer's best performing crop insurance combinations under different risk aversion levels and scenarios for ENSO phases. These crop insurance combinations were selected based on the estimated farm net returns for a one-year planning horizon using 990 iteration for each ENSO phase and 2,970 for "all years." The outcomes presented in this study represent the average net returns. However, it is important to indicate that these results are probabilistic distributions that include all potential combinations of climate and prices by ENSO phase. As expected, the yearly average predicted returns decreased with increased risk aversion levels. Farmers with higher risk aversion will engage in more protective insurance products, whereas risktaker farmers will prefer more flexible insurance contracts. In addition, a comparison of farm net returns, using a t-test, between the ENSO phases and "all years" shows that the latter displays statistically lower average net returns than the ENSO phases. Lower returns for "all years" are expected since it means that the insurance contract did not include climate forecasts information in its farm decisions framework. We emphasize the fact that the net returns by ENSO phase are those obtained using the ENSO-based climate information, whereas returns for "all years" are those not using climate information (naive).

The empirical results show that, independently of the ENSO phase, higher returns were simulated for low or no insurance coverage for cotton combined with high coverage for peanut. The highest net returns were obtained during El Niño years with the no insurance option for cotton and 75\% APH for peanut (average $=\$ 18,265 /$ year and $95 \%$ confidence interval $(\mathrm{CI})$ of $\left.\mathrm{CI}_{(95 \%)}=[17,027-19,502]\right)$. The lowest return was obtained for neutral years when the $85 \%$ CRC coverage was selected for cotton and no insurance was selected for peanut $\left(\right.$ average $=\$ 12,947$ and $\left.\mathrm{CI}_{(95 \%)}=[11,741-14,154]\right)$.

As indicated above, differences were also found depending on the farmer's risk aversion level. For low risk aversion $\left(R_{r}=0\right.$ and 1$)$, the optimization analysis showed the same best crop insurance combinations across ENSO phases. The analysis suggests that under risk neutrality $\left(R_{r}=0\right)$ and normal risk aversion $\left(R_{r}=1\right)$, the best crop insurance combination are no coverage or CAT coverage for cotton and $65 \%$ to $75 \%$ APH for peanut.

For higher risk aversion levels $\left(R_{r}=2,3\right.$, and 4), the crop insurance combinations differed across ENSO phases and risk aversion levels. For cotton, a slightly increased coverage of CAT insurance was observed. For peanut, however, lower coverage levels were selected. For the case of "all years," no insurance for both crops resulted in the highest net income. Lower coverage for peanut at higher risks potentially occurs for two reasons. First, our maximization model involved a whole-farm maximization, which included the interaction of both farm crops. Although peanut coverage decreased, the coverage of cotton increased and overall insurance was consistent with levels of risk aversion. Second, crop insurance coverage is just one of the ways that farmers can reduce their exposure to risk. Peanut is fairly resistant to changes in the extremes of its yield variability, and major impacts in production due to diseases and nematodes can be managed at a lower cost than the insurance premium.

\section{Insurer's Best Performing Crop Insurance Combinations}

To facilitate the comparison between the farmer's and insurer's outcomes, the minimum expected losses for the insurer were transformed to maximum gains by applying duality. Duality is a property in optimization analysis that allows converting a primal problem (i.e., the minimization of the cost function) into a dual problem (i.e., the maximization of the revenue function). The optimization analysis for the insurer shows average gains ranging from $\$ 23$ to $\$ 258 \mathrm{ha} /$ year. Minimum gain occurred for a CAT contract for cotton and $70 \%$

Table 2. Farmer's best crop insurance combinations according to average net returns by ENSO phase and level of risk aversion.

\begin{tabular}{|c|c|c|c|c|c|c|c|c|}
\hline \multirow{2}{*}{$\begin{array}{l}\text { Level } \\
\text { of Risk } \\
\text { Aversion }\end{array}$} & \multicolumn{2}{|c|}{ All Years } & \multicolumn{2}{|c|}{ El Niño } & \multicolumn{2}{|c|}{ Neutral } & \multicolumn{2}{|c|}{ La Niña } \\
\hline & Insurance $[\mathrm{a}]$ & $\begin{array}{c}\text { Avg. } \\
\text { Returns }[\mathrm{b}]\end{array}$ & Insurance & $\begin{array}{l}\text { Avg. } \\
\text { Returns }\end{array}$ & Insurance & $\begin{array}{l}\text { Avg. } \\
\text { Returns }\end{array}$ & Insurance & $\begin{array}{c}\text { Avg. } \\
\text { Returns }\end{array}$ \\
\hline \multicolumn{9}{|c|}{$0:$ Risk neutrality } \\
\hline & NOINS-75APH & 17,065 & NOINS-75APH & 18,265 & NOINS-75APH & 17,641 & NOINS-75APH & 18,022 \\
\hline \multicolumn{9}{|c|}{ 1: Normal risk aversion } \\
\hline & NOINS-75APH & 16,519 & NOINS-75APH & 17,561 & NOINS-75APH & 17,085 & NOINS-75APH & 17,346 \\
\hline \multicolumn{9}{|c|}{ 2: Rather averse } \\
\hline & NOINS-NOINS & 14,506 & CAT-65APH & 15,553 & CAT-70APH & 15,543 & NOINS-70APH & 15,086 \\
\hline \multicolumn{9}{|c|}{ 3: Very averse } \\
\hline & NOINS-NOINS & 13,780 & CAT-65APH & 14,905 & CAT-70APH & 14,768 & NOINS-70APH & 14,452 \\
\hline \multicolumn{9}{|c|}{ 4: Almost paranoid } \\
\hline & NOINS-NOINS & 13,107 & CAT-65APH & 14,276 & CAT-70APH & 14,016 & NOINS-70APH & 13,832 \\
\hline
\end{tabular}




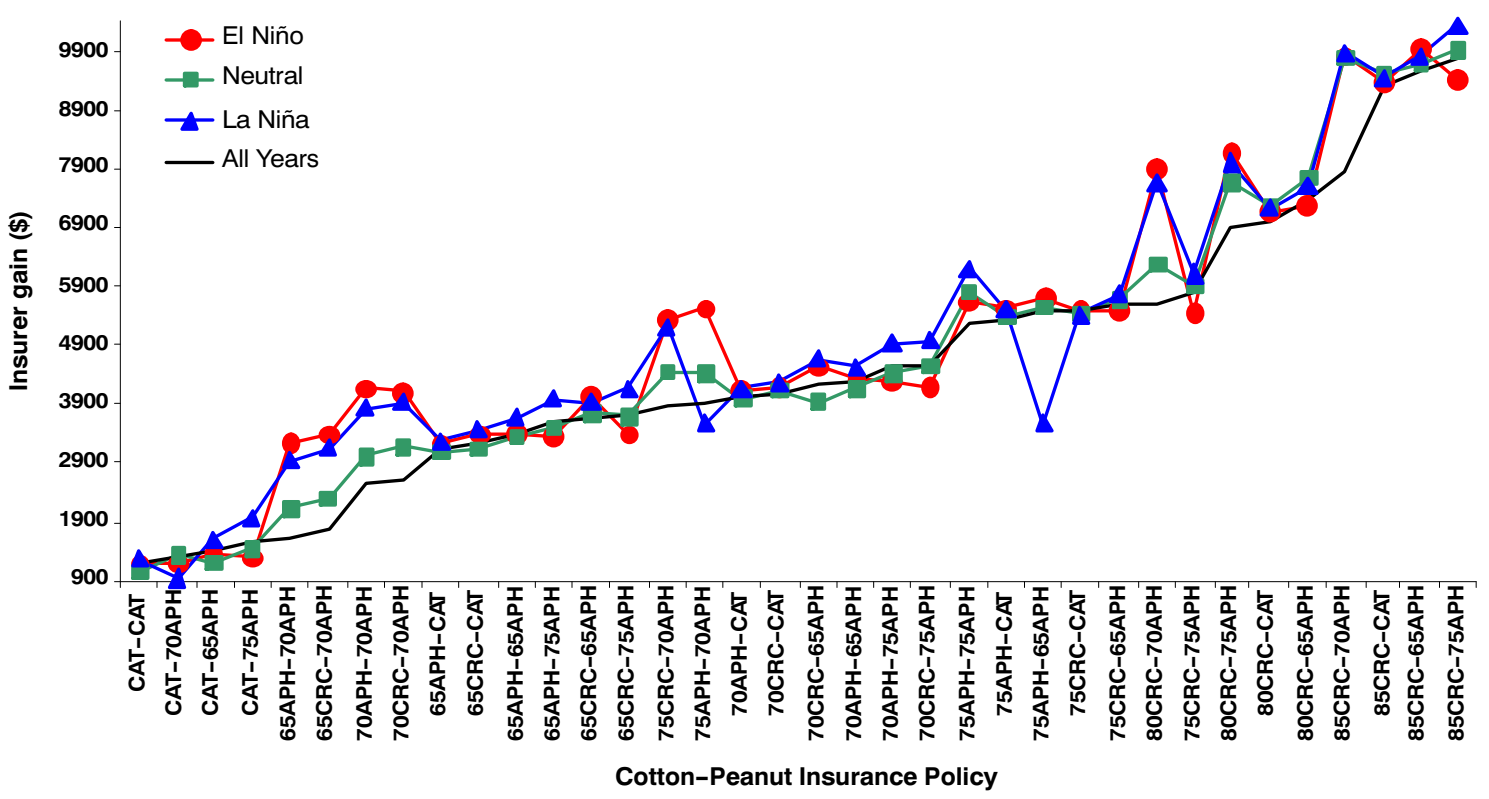

Figure 1. Average gain of insurer per crop insurance contract and ENSO phase.

APH for peanut for La Niña and El Niño years, whereas this was CAT for cotton and peanut for neutral years. Maximum gains occurred for $85 \% \mathrm{CRC}$ for cotton and $75 \% \mathrm{APH}$ for peanut for La Niña and neutral years, whereas $85 \%$ CRC for cotton and $65 \%$ APH for peanut gave the maximum gains for El Niño years. Figure 1 summarizes the average gains by insurance contracts and ENSO phase. The lines cross at several points, indicating different climate impacts by insurance contract.

Table 3 shows the optimum crop insurance contracts that $90 \%, 95 \%$, or $99 \%$ of the time (risk level) have higher returns than a specific threshold (risk value). The 85CRC-65APH contract was the best combination for El Niño years. However, if the insurer wants to obtain returns higher than $\$ 4,000$ (or $\$ 100 /$ ha) $95 \%$ of the time, then $75 \mathrm{APH}-\mathrm{CAT}$ would be the best contract. Likewise for El Niño years, the best contract to obtain returns higher than $\$ 2,000$ (or $\$ 50 /$ ha) $99 \%$ of the time would be 75APH-CAT. There was no contract available that had a greater than $\$ 4,000$ gain $99 \%$ of the time.

\section{Synergies And Conflicts Between FARMer AND INSURER}

Figure 2 combines the risk-neutral farmer and the riskneutral insurer proportion of maximum net returns by ENSO phase and crop insurance contract. As expected, conflicts of interest are found at the extremes of the graphs presented in figure 2. Maximum gains for farmers (insurers) imply minimum gains for insurers (farmers). The 85CRC-CAT contract was the lowest net return generator for the farmer, while it brought one of the greatest gains to the insurer. Likewise, contracts such as CAT-75APH for El Niño and neutral and CAT-70APH for La Niña had the greatest net returns for the farmer with the lowest gains for the insurer.

However, figure 2 also depicts synergies between insurer and farmer. Synergies can be found in areas where percentages of insurer gain and farmer net return are alike. Considering the $40 \%$ to $60 \%$ interval a reasonable range where insurer and farmer would converge in their interests, it is possible to find some synergic crop insurance alternatives. Specifically,
Table 3. Insurer's best crop insurance contract according to risk values and risk levels.

\begin{tabular}{|c|c|c|c|}
\hline \multirow{2}{*}{$\begin{array}{c}\text { Risk Value } \\
(\$)\end{array}$} & \multicolumn{3}{|c|}{ Risk Level } \\
\hline & $90 \%$ & $95 \%$ & $99 \%$ \\
\hline \multicolumn{4}{|l|}{ El Niño } \\
\hline$<-4000$ & 85CRC-65APH & 85CRC-65APH & 85CRC-65APH \\
\hline$-4000-2000$ & 85CRC-65APH & 85CRC-65APH & 85CRC-65APH \\
\hline$-2000-0$ & 85CRC-65APH & 85CRC-65APH & 85CRC-65APH \\
\hline $0-2000$ & 85CRC-65APH & 85CRC-65APH & 85CRC-65APH \\
\hline $2000-4000$ & 85CRC-65APH & 85CRC-65APH & 75APH-CAT \\
\hline$>4000$ & 85CRC-65APH & 75APH-CAT & $\mathrm{NA}^{[\mathrm{a}]}$ \\
\hline \multicolumn{4}{|l|}{ Neutral } \\
\hline$<-4000$ & 85CRC-75APH & 85CRC-75APH & 85CRC-75APH \\
\hline$-4000-2000$ & 85CRC-75APH & 85CRC-75 & 85CRC- \\
\hline$-2000-0$ & 85CRC-75APH & 85CRC-75APH & 85CRC-75APH \\
\hline $0-2000$ & 85CRC-75APH & 85CRC-75APH & 65АРH-CAT \\
\hline $2000-4000$ & 85CRC-75APH & 85CRC-75APH & 75APH-CAT \\
\hline$>4000$ & 85CRC-75APH & 75APH-CAT & NA \\
\hline \multicolumn{4}{|l|}{ La Niña } \\
\hline$<-4000$ & 85CRC-75APH & 85CRC-75APH & 85CRC-75APH \\
\hline$-4000-2000$ & 85CRC-75APH & 85CRC-75APH & 85CRC-75APH \\
\hline$-2000-0$ & 85CRC-75APH & 85CRC-75APH & 85CRC-CAT \\
\hline $0-2000$ & 85CRC-75APH & 85CRC-75APH & 70APH-CAT \\
\hline $2000-4000$ & 85CRC-75APH & 85CRC-75APH & 75APH-CAT \\
\hline$>4000$ & 85CRC-CAT & 85CRC-CAT & NA \\
\hline \multicolumn{4}{|l|}{ All years } \\
\hline$<-4000$ & 85CRC-75APH & 85CRC-75APH & $85 \mathrm{CRC}-75 \mathrm{APH}$ \\
\hline$-4000-2000$ & 85CRC-75APH & 85CRC-75APH & 75APH-65APH \\
\hline$-2000-0$ & 85CRC-75APH & 85CRC-75APH & 65APH-CAT \\
\hline $0-2000$ & 85CRC-75APH & 85CRC-75APH & 75APH-CAT \\
\hline $2000-4000$ & 85CRC-75APH & 85CRC-CAT & NA \\
\hline$>4000$ & 85CRC-CAT & NA & NA \\
\hline
\end{tabular}

[a] NA means insurance contract not available for those conditions.

the synergic crop insurances are: 75APH-75APH and 75CRC-CAT for all ENSO phases, 75APH-CAT for neutral and La Niña, 75APH-70APH for El Niño, and 80CRC-70APH and 75APH-65APH for neutral. Neutral years had five synergetic contracts, whereas El Niño and La Niña only had three. 

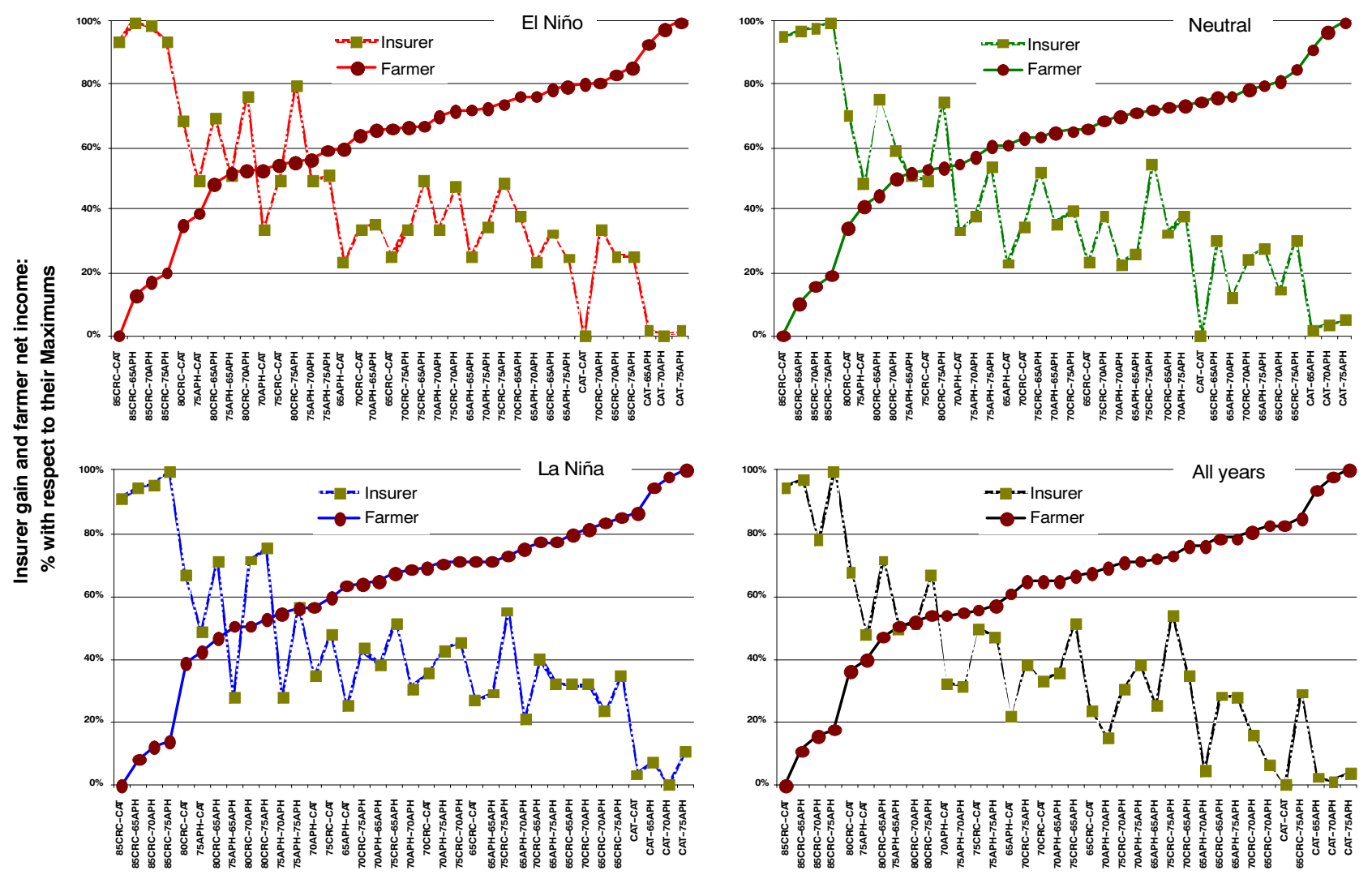

Cotton-Peanut Insurance Policy

Figure 2. Insurer gain and farmer net income expressed by percentage of their maximum returns by crop insurance contract and ENSO phase.

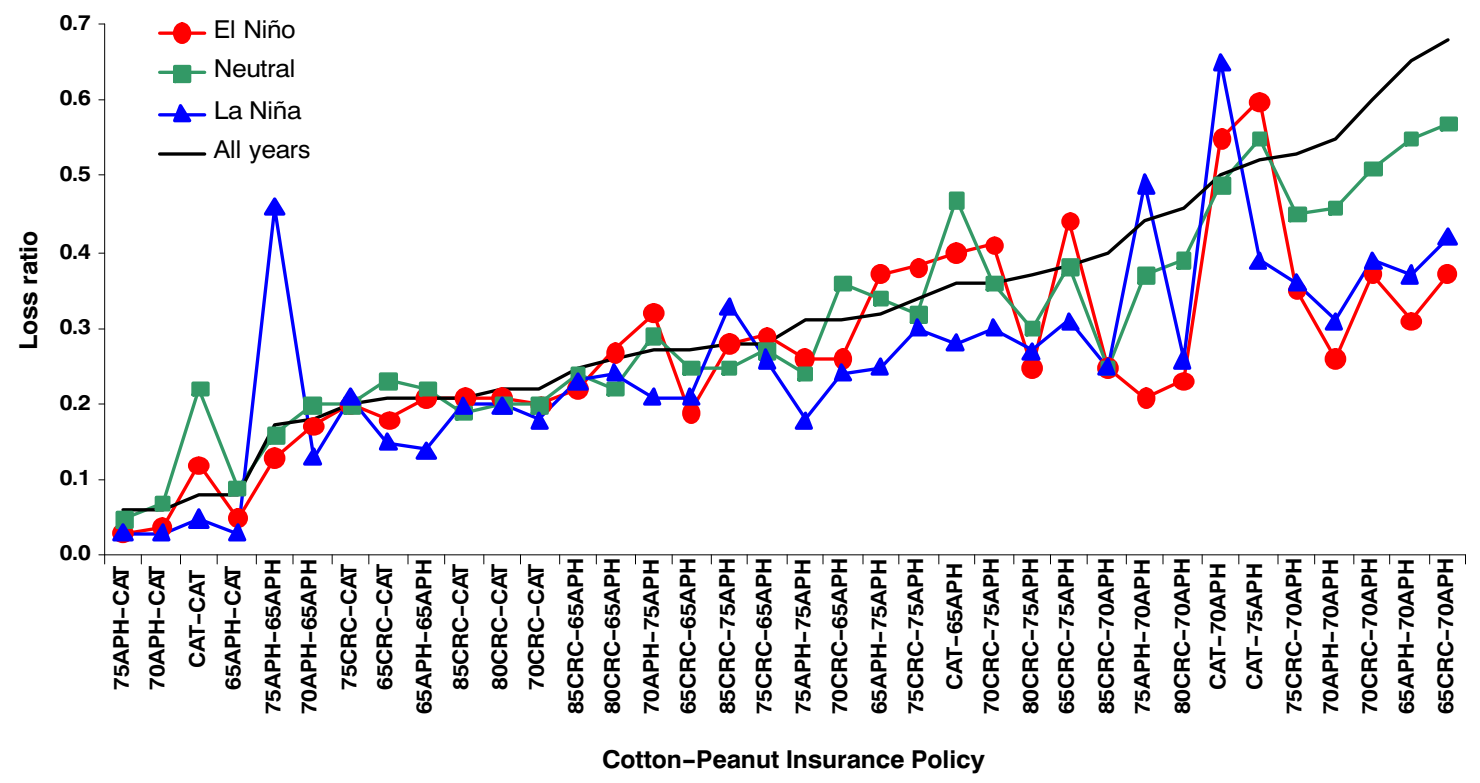

Figure 3. Average loss ratio per crop insurance contract and ENSO phase.

\section{Insurer Loss Ratios by Optimal Crop InSURANCE}

\section{ConTracts}

The empirical results show that the average LR for all years was 0.32 , indicating that only $32 \%$ of the premium received was used to pay indemnities. It is important to indicate that these results are consistent with the average insurer's
LRs currently reported by the FCIC for Florida, which were 0.64 for peanuts and 0.36 for cotton. Differences between our estimated LR and the FCIC LR could be explained in part by the fact that our analyses did not include spatial variability. The spatial variability implicit in the FCIC LR would exert substantial impacts to the LR index. When accounting for 


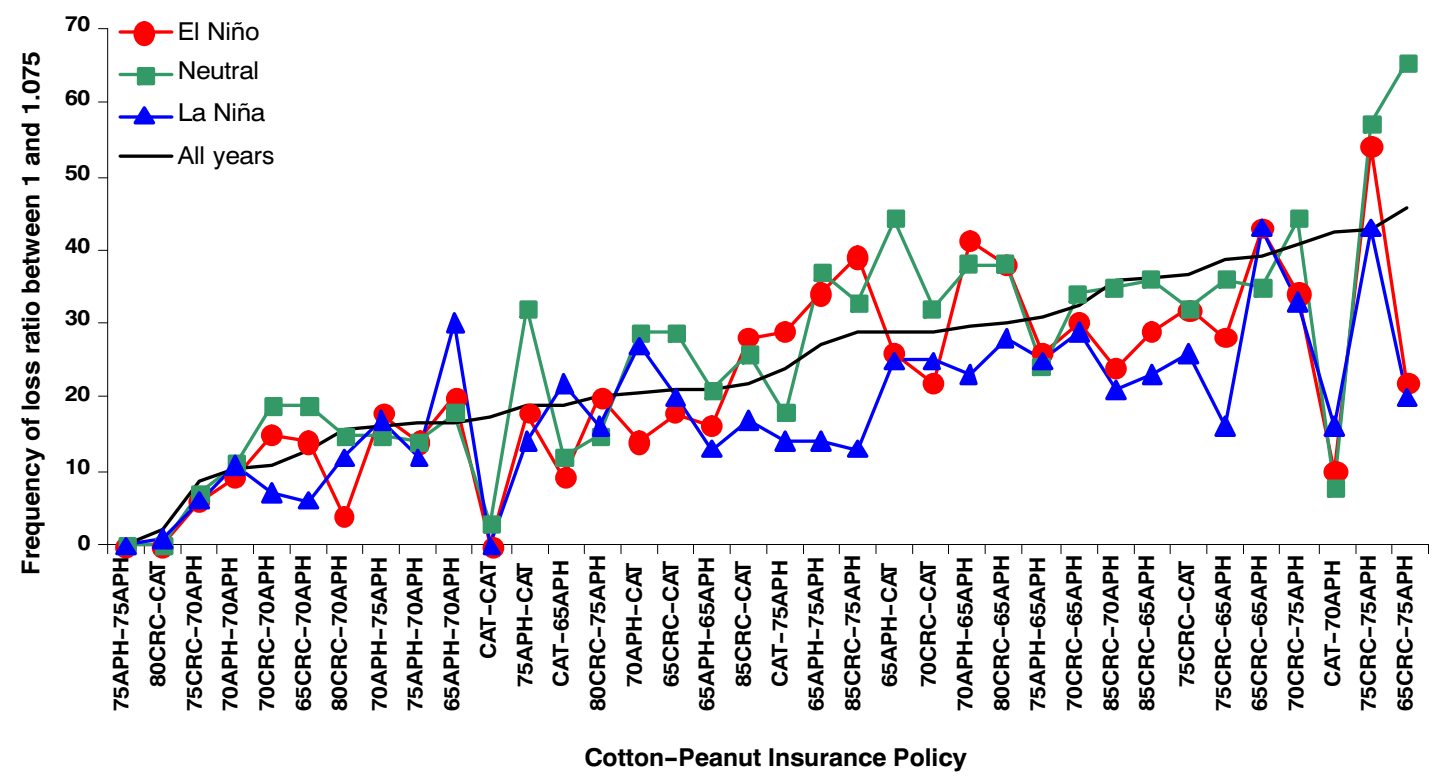

Figure 4. Frequency or number of times the loss ratio was between 1 and $\mathbf{1 . 0 7 5}$ per crop insurance contract and ENSO phase.

ENSO phase, this ratio decreased to 0.27 for El Niño, 0.30 for neutral, and 0.26 for La Niña, suggesting that the value of the climatic information has a greater significance for insurers than for farmers. Figure 3 shows the average LR by insurance contract and ENSO phase. The lowest LRs occurred for $65 \%$, $70 \%$, and $75 \%$ APH for cotton and CAT for peanut contracts during La Niña, and for 75APH-CAT contracts during El Niño and neutral. The greatest LRs occurred for CAT-75APH for El Niño, 65CRC-70APH for neutral, and CAT-70APH for La Niña.

The results presented above are far from a 1.075 long-run LR targeted by the FCIC in 2005. No insurance contract reached on average an LR between 1 (indemnity is equal to premium) and 1.075 (7.5\% beyond premium loss). However, figure 4 shows that most of the contracts had some frequency that reached such a range of target LR. There was great variability in such frequency, influenced primarily by climate variability. Depending on ENSO phase, the frequency varied from zero (75APH-75APH and 80CRC-CAT contracts) to 65 in neutral years (65CRC-75APH), to 54 in El Niño years (75CRC-75APH), and to 43 in La Niña years (65CRC$65 \mathrm{APH})$.

Climate variability had a great influence on the farmer's net return and the insurer's gain, impacting also the overall LR and the probability of reaching a target LR. This climatic impact was noticed be the highest for the 65CRC-75APH contract, which had $41 \%$ higher (neutral) and 55\% lower (El Niño and La Niña) probabilities of being in the LR target range than "all years." Insurance policies within the FCIC targeted LR may increase the range of synergic crop insurance alternatives, improving expected farmers' returns. This is an area that merits further research.

It is important to indicate that the local insurer's LRs reported in this article consider only two crops in one county and are not intended for evaluating the whole U.S. crop insurance market. To do so, further analysis including a broader spatial dimension is needed.

\section{Conclusions}

This study analyzed the potential tradeoffs between farmers and insurers in the selection of an optimal crop insurance contract in the presence of climate variability. Our results show that our representative farmer's net returns is significantly affected by the crop insurance policy purchased and the risk aversion level selected. Long-run gains for insurers are directly related to the premium received and risk levels. In addition, year-to-year, ENSO-based climate variability affected farmer returns and insurer gains according to crop insurance contracts.

Although we did find evidence of conflicting interests between insurers and farmers regarding crop insurance selection, their best choices are seldom contradictory. So, if both parties are willing to show flexibility regarding their best selections, then farmers and insurers can both attain longterm sustainability without jeopardizing their economic stability. However, only the insurer has the capacity to change the underwritten crop insurance policy contracts under the commitment to help farmers attain economic stability. Therefore, the insurer would have a greater ability to resolve these conflicts of interests. Using ENSO-based climate forecast would be a factor in this decision selection process.

Another important outcome is that the average loss ratio found for insures was 0.32 , that is, only $32 \%$ of the premium received was used to pay indemnities. This ratio is significantly lower than a 1.075 long-run loss ratio that was targeted by policy makers, suggesting that, for the region and crops considered, significant room exists for decreasing farmers' premiums while still attaining economically feasible loss ratio targets.

In sum, the results of this study agree with the spirit of Changnon et al. (1999), who suggest that climate information can help farmers and insurers mitigate losses related to climate variability. Climate information can help farmers to select crop insurance that maximizes their net returns. In addition, this kind of information may assist insurers to assess risks more precisely. Thus, insurers and farmers can bridge their divergent interests by improving their understanding of the effect of climate conditions on the development of sustainable business plans. 
One caveat in this study is that our analysis focuses on one specific geographical region, ignoring the spatial dimension. Consequently, studying the value of location on the impact of climate and crop insurance on farm net returns could be an area for future refinement of the model implemented here. Additionally, further research might also benefit by including farm programs and studying their interaction with crop insurances.

\section{ACKNOWLEDGEMENTS}

This work has been supported by the NOAA Climate Programs Office, the USDA Risk Management Agency, the USDA Cooperative State Research, Education and Extension Service, and the Southeast Climate Consortium (http://seclimate.or g/).

\section{REFERENCES}

Abbaspour, K. 1994. Bayesian risk methodology for crop insurance decisions. Agric. and Forest Meteorology 71(3-4): 297-314.

Baigorria, G., J. Jones, and J. O'Brien. 2008. Potential predictability of crop yield using an ensemble climate forecast by a regional circulation model. Agric. and Forest Meteorology 148(8-9): 1353-1361.

Boote, K., J. Jones, and G. Hoogenboom. 1998. Simulation of crop growth: CROPGRO model. In Agricultural Systems Modeling and Simulation, 651-692. R. Peart and R. Curry, eds. New York, N.Y.: Marcel Dekker.

Cabrera, V. E., C. Fraisse, D. Letson, G. Podestá, and J. Novak. 2006. Impact of climate information on reducing farm risk by optimizing crop insurance strategy. Trans. ASABE 49(4): 1223-1233.

Cabrera, V. E., D. Letson, and G. Podestá. 2007. The value of the climate information when farm programs matter. Agric. Systems 93: $25-42$.

Changnon, S., E. Fosse, and E. Lecomte. 1999. Interactions between the atmospheric sciences and insurers in the United States. Climatic Change 42(1): 51-67.

Charnes, A., and W. Cooper. 1959. Chance-constrained programming. Mgmt. Sci. 6: 73-79.

Chen, C., and C. Chang. 2005. The impact of weather on crop yield distribution in Taiwan: Some new evidence from panel data models and implications for crop insurance. Agric. Econ. 33(supp. 3): 503-511.

Dalton, T., G. Porter, and N. Winslow. 2004. Risk management strategies in humid production regions: A comparison of supplemental irrigation and crop insurance. Agric. and Resource Economics Review 33(2): 220-232.

Fraser, R. 2004. On the use of targeting to reduce moral hazard in agri-environmental schemes. J. Agric. Econ. 55(3): 525-540.

Gill, P., W. Murray, B. Murtagh, M. Saunders, and M. Wright. 2000. GAMS/MINOS in GAMS: Solver Manuals. Washington, D.C.: GAMS Development Corp.

Hansen, J. 2002. Realizing the potential benefits of climate prediction to agriculture: Issues, approaches, challenges. Agric. Systems 74(3): 309-330.

Hansen, J., A. Hodges, and J. Jones. 1998. ENSO influences in agriculture in the southeastern United States. J. Climate 11(3): 404-411.

Hardaker, J., R. Huirne, J. Anderson, and G. Lien. 2004. Coping with Risk in Agriculture. 2nd ed. Wallingford, U.K.: CABI Publishing.

Hill, H., and J. Mjelde. 2002. Challenges and opportunities provided by seasonal climate forecasts: A literature review. $J$. Agric. and Applied Econ. 34(3): 603-632.

Jagtap, S., J. Jones, P. Hildebrand, D. Letson, J. O'Brien, G. Podestá, D. Zierden, and F. Zazueta. 2002. Responding to stakeholder's demands for climate information: From research to applications in Florida. Agric. Systems 74(3): 415-430.

JMA. 1991. Climate Charts of Sea-Surface Temperature of the Western North Pacific and the Global Ocean. Tokyo, Japan: Japan Meteorological Agency, Marine Department.

Jones, J., J. Hansen, F. Royce, and C. Messina. 2000. Potential benefits of climate forecasting to agriculture. Agric. Ecosystems and Environ. 82: 169-184.

Jones, J., G. Hoogenboom, C. Porter, K. Boote, W. Batchelor, L. Hunt. P. Wilkens, U. Singh, A. Gijsman, and J. Ritchie. 2003. The DSSAT cropping system model. European J. Agron. 18(3-4): 235-265.

Ker, A., and P. McGowan. 2000. Weather-based adverse selection and the U.S. crop insurance program: The private insurance company perspective. J. Agric. and Resource Econ. 25(2): 386-410.

Letson, D., G. Podestá, C. Messina, and A. Ferreyra. 2005. The uncertain value of perfect ENSO phase forecasts: Stochastic agricultural prices and intra-phase climatic variations. Climatic Change 69(2-3): 163-196.

Liu, J., C. Men, V. E. Cabrera, S. Uryasev, and C. W. Fraisse. 2008. Optimizing crop insurance under climate variability. J. Applied Meteorology and Climatology 47(10): 2572-2580.

Mahul, O. 2001. Optimal insurance against climatic experience. American J. Agric. Econ. 83(3): 593-604.

Mavromatis, T, S. Jagtap, and J. Jones. 2002. El Niño Southern Oscillation effect on peanuts yield and $\mathrm{N}$ leaching. Climate Res. 22(2): 129-140.

Menrad, K., and T. Hirzinger. 2005. Impacts of the genetic modification of plants on crop insurance schemes. Berichte über Landwirtschaft 83(2): 252-277.

Messina, C., J. Jones, and C. Fraisse. 2003. Development of cotton CROPGRO crop model. Staff Paper Series 05-05. Southeast Climate Consortium.

Mjelde, J., and H. Hill. 1999. The effect of the use of improved climate forecasts on variable costs, input usage, and production. Agric. Systems 60(3): 213-225.

Mjelde, J., T. Thompson, and C. Nixon. 1996. Government institutional effects on the value of seasonal climate forecasts. American J. Agric. Econ. 78(1): 175-188.

NASS. 2007. Corn and cotton production in Florida: 1939-2003. Washington, D.C.: USDA National Agricultural Statistics Service. Available at: www.nass.usda.gov.

Nnaji, A. O. 2001. Forecasting seasonal rainfall for agricultural decision-making in northern Nigeria. Agric. and Forest Meteorology 107(3): 193-205.

Podestá G., D. Letson, C. Messina, F. Royce, R. Ferreyra, J. Jones, J. Hansen, I. Llovet, M. Grondona, and J. O'Brien. 2002. Use of ENSO-related climate information in agricultural decision making in Argentina: A pilot experience. Agric. Systems 74(3): 371-392.

Prekopa, A. 1995. Stochastic Programming. Dordrecht, The Netherlands: Kluwer Academic.

Rockafellar, R., and S. Uryasev. 2002. Conditional value-at-risk for general loss distributions. J. Banking and Finance 26(7): 1443-1471.

Rupp, R. 1991. Rupp's Insurance and Risk Management Glossary. Chatsworth, Cal.: Nils Publishing.

Schneider, J., and J. Garbrecht. 2003. A measure of usefulness of seasonal precipitation forecasts for agricultural applications. Trans. ASAE 46(2): 257-267.

Turvey, C., G. Nayak, and D. Sparling. 1999. Reinsuring agricultural risk. Canadian J. Agric. Econ. 47(3): 281-291.

USTR. 2006. Repealing cotton subsidy program. Press release, February 2006. Washington, D.C.: Office of the U.S. Trade Representative.

Wang, H., and H. Zhang. 2003. On the possibility of a private crop insurance market: A spatial statistics approach. J. Risk and Insurance 70(1): 111-124. 
